\title{
The Present and Future of Museum Accessibility for People with Visual Impairments
}

\author{
Saki Asakawa ${ }^{1}$, João Guerreiro ${ }^{1}$, Dragan Ahmetovic ${ }^{1}$, Kris M. Kitani ${ }^{1}$, Chieko Asakawa ${ }^{1,2}$ \\ ${ }^{1}$ Carnegie Mellon University, ${ }^{2}$ IBM Research \\ \{sakiasa, jpvguerreiro, dragan1\}@cmu.edu, \{kkitani, chiekoa\}@cs.cmu.edu
}

\begin{abstract}
People with visual impairments (PVI) have shown interest in visiting museums and enjoying visual art. Based on this knowledge, some museums provide tactile reproductions of artworks, specialized tours for PVI, or enable them to schedule accessible visits. However, the ability of PVI to visit museums is still dependent on the assistance they get from their family and friends or from the museum personnel. In this paper, we surveyed 19 PVI to understand their opinions and expectations about visiting museums independently, as well as the requirements of user interfaces to support it. Moreover, we increase the knowledge about the previous experiences, motivations and accessibility issues of PVI in museums.
\end{abstract}

\section{CCS Concepts}

-Human-centered computing $\rightarrow$ Empirical studies in accessibility; Accessibility technologies; - Social and professional topics $\rightarrow$ People with disabilities;

\section{Author Keywords}

Museum accessibility; visual impairments; indoor navigation;

\section{INTRODUCTION}

People with visual impairments (PVI) are interested in visiting museums and enjoying visual art $[6,7]$. In addition, laws such as the Americans with Disabilities Act [1] state that museums should be accessible to people with disabilities. As a consequence, researchers are trying to improve the experience of PVI in museums $[2,5,9,11,14]$. Moreover, some museums provide specialized tours or workshops $[8,12]$, while others allow to "negotiate" for accessible visits [10]. Yet, the ability of PVI to visit art museums is still dependent on the assistance they get from their family, friends or the museum personnel.

In order to understand what PVI value the most in their museum experiences, previous research $[3,4,6]$ has shown the positive impact of tactile replicas or reproductions and of specialized guided tours. These services are valuable, but they still fail to support an independent experience where PVI can enjoy art at their own pace. We present a survey with 19 PVI

\footnotetext{
Permission to make digital or hard copies of part or all of this work for personal or classroom use is granted without fee provided that copies are not made or distributed for profit or commercial advantage and that copies bear this notice and the full citation on the first page. Copyrights for third-party components of this work must be honored. For all other uses, contact the owner/author(s).

ASSETS '18 October 22-24, 2018, Galway, Ireland

(C) 2018 Copyright held by the owner/author(s).

ACM ISBN 978-1-4503-5650-3/18/10 . .\$15.00

DOI: https : //doi .org/10 . 1145/3234695 . 3240997
}

aiming to understand their willingness to visit museums by themselves and we investigate the requirements of solutions designed for such purpose. Moreover, we extend the knowledge about previous experiences of PVI in museums, their motivations to visit them and the accessibility issues they face.

Results show that an independent experience is valuable because PVI can enjoy visual art at their own pace; they do not want to rely on their sighted friends all the time; and the quality of the visual descriptions is highly dependent on the person providing them. Moreover, they want to receive auditory descriptions in front (and not just near) of each artwork.

\section{SURVEY}

We surveyed 19 PVI (P1-P19) in-person to gain a better understanding of their previous experiences in museums, their motivations to visit them, and the accessibility issues they face therein. Most importantly, we wanted to grasp their perspectives on being able to visit museums by themselves and the requirements for interfaces that support an independent experience. Their ages ranged from 29 to 72 years old (10 males, 9 females). Sixteen were totally blind, and three were legally blind. All participants have visited museums before. Four participants visit museums more than twice a year, two visit once a year, five every two years or less, and eight have visited museums just a few times in their lives. We use 5-Point Likert Items (from 1 - "very bad/not at all" - to 5 - "very good/very much") and open questions that we address in the next section.

\section{FINDINGS}

\section{Previous Experiences}

Participants had contrasting perspectives about their museum experiences (overall rating: $\mathrm{M}=3.26, \mathrm{SD}=0.87$ ). Negative or neutral ratings resulted from mobility issues or inaccessible content or artwork (detailed in Accessibility Issues). Positive ratings support prior research $[3,4,6]$ valuing private or specialized tours provided by the museums ("The director was just amazing, (...) he took us to different places in the castle that really aren't accessible to the public" (P6)). Also, sensing tactile replicas or reproductions (rating for past tactile experiences: $\mathrm{M}=4.71, \mathrm{SD}=0.59$ ), even if only a few are available, is essential for a positive experience ("I love artwork anytime I have an opportunity to examine tactile art" (P9)).

\section{Motivation}

All participants showed interest in visiting museums (contrasting with [13]), mainly to gain knowledge (15 participants) and to socialize with their friends/family (13). Their motivation 
to learn was often referred together with the desire to feel the museum "atmosphere", in opposition to gain knowledge elsewhere ("If [I] go to a museum, it's because I wanna learn what's there and I want a firsthand experience on site. I don't wanna dry reading a book" (P19)).

\section{Accessibility Issues}

The main accessibility issues found in museums can be categorized into Mobility Issues and Inaccessible Artworks.

\section{Mobility Issues}

Fourteen participants have never visited a museum by themselves. Moreover, the difficulties to move around independently discouraged most participants from visiting museums more often ("A part of the problem in museums is that it's a huge, huge open place and if I were wandering around by myself, I would just be getting lost." (P19)). The five participants who visited museums by themselves were assisted by museum escorts or attended specialized tours for PVI.

\section{Inaccessible Artworks}

The lack of accessibility of artworks severely impacts the experience of PVI in museums. It is known $[3,6]$ and reinforced by our survey that being able to sense tactile reproductions or replicas is very important to a fulfilling experience, but it is not always available ("My experience (...) has been very poor. Usually I have to have a sighted guide with me to explain... and I've very been frustrated for you can't touch things in museums, yes very frustrated!' (P14)). Moreover, the quality of such reproductions is also relevant and should not be neglected ("Like sometimes someone would try and get a painting, try to make it tactile and sometimes yes it has texture, but [it] doesn't always convey the meaning of the artwork" (P13)).

Besides tactile exposure, all participants enjoy having access to audio descriptions of the artworks. As expected, guided tours were found to be enriching and pleasant due to the expertise of the museum personnel. Although audio guides and their descriptions are also prepared by experts, several participants referred to the devices lack of accessibility ("The problem is that the device I used was not that friendly...there were audio descriptions but you have to put into the code of the location you are [which is only provided visually]" (P16)).

Usual alternatives to provide descriptions of visual information are family and friends. Still, it depends on their availability ("If they explain and if they have time, absolutely that's more fulfilling." (P9)) and on their ability to provide good descriptions ("It depends on who you go with. Some people are very expressive and they are very descriptive. But other people are...not really giving me much...They don't know exactly what I wanna know" (P9)). In addition, several participants referred that they "do not want to be a burden" to their sighted companions.

\section{Requirements to Support an Independent Experience}

The previous sections suggest that PVI are interested in having more control over their museum experiences, which could lead them to visit museums more often (by themselves or with sighted peers). In our survey, we tried to understand the relevance of features that could improve museum accessibility and increase the opportunities for PVI to enjoy visual art.
All participants were familiar with navigation apps and eighteen of them mentioned that an indoor navigation system would be important $(\mathrm{M}=4.68, \mathrm{SD}=0.75)$ to enable an independent museum experience (e.g., "I would be more motivated to visit museums, if some museums have a navigation app" (P2)). Prior formative studies do not refer to navigation assistance $[3,6,7,13]$, as they focus on the past and current experiences of PVI in museums, which do not support independent navigation. However, not being able to find the location of accessible collections and artworks is often referred as an obstacle [6].

Eighteen participants pointed out that detailed audio content is necessary to gain new knowledge (importance of audio descriptions: $M=4.74, S D=0.65)$. Moreover, participants felt that it is important to listen to the audio contents in front of the artworks $(\mathrm{M}=4.47, \mathrm{SD}=0.77)$ to have a similar experience to sighted people ("I think I want to be the right in front of the art, not near" (P2)). Some participants prefer to listen to human voices (human voices likeability: $\mathrm{M}=4.68 \mathrm{SD}=0.75$ ) as long as they are neutral rather than too emotional ("human emotions might influence the experience (...) I like objective descriptions" (P11)). However, most participants had no preference since they are used to synthesized speech (synthesized speech likeability: $\mathrm{M}=4 \mathrm{SD}=0.94)$. When asked about the content of the audio descriptions, preferences went towards an introduction/summary (relevant of content type: $\mathrm{M}=4.89 \mathrm{SD}=0.31$ ), the history ( $M=4.68 \mathrm{SD}=0.48)$, and a detailed visual description $(\mathrm{M}=4.42 \mathrm{SD}=0.90)$ of the artwork, followed by detailed descriptions of the technique used $(\mathrm{M}=3.84 \mathrm{SD}=1.21)$. Moreover, participants often referred that it would be good to be able to adjust the length of (or skip) the descriptions.

Overall, when considering an app that provided both navigation assistance and detailed audio feedback, participants stated that they would be motivated to visit museums by themselves $(\mathrm{M}=4.78, \mathrm{SD}=0.41)$. For instance, they stated: "If such functions are available, I may start going to museums by myself", (P10); and 'If it's good art that I can use and know that I'm gonna get something out of the museum... It would definitely increase my desire" (P15). Also, they mentioned it would be useful when visiting museums with sighted companions.

\section{CONCLUSION}

We performed a survey with 19 PVI to understand their current museum experiences and the accessibility problems they face, and to grasp the requirements for solutions that support an independent museum experience. We found that participants want to visit museums, as they want to obtain new knowledge and they value the on-site experience. However, inaccessible artworks and the lack of independence discourages them to visit museums more often, due to an over-reliance on their friends and family or on the intermittent availability of specialized guided-tours for PVI. Future solutions aimed to support an independent museum experience should provide navigation assistance as well as detailed audio content that should be read when the user is in front of the artwork.

\section{ACKNOWLEDGMENTS}

We would like to thank all participants of our survey. This work was sponsored by Shimizu Corp. 


\section{REFERENCES}

1. 2009. Expanding Your Market: Maintaining Accesibility in Museums. (2009).

https://www . ada.gov/business/museum_access.htm Accessed: 2018-04-12.

2. Giorgos Anagnostakis, Michalis Antoniou, Elena Kardamitsi, Thodoris Sachinidis, Panayiotis Koutsabasis, Modestos Stavrakis, Spyros Vosinakis, and Dimitris Zissis. 2016. Accessible Museum Collections for the Visually Impaired: Combining Tactile Exploration, Audio Descriptions and Mobile Gestures. In Proceedings of the 18th International Conference on Human-Computer Interaction with Mobile Devices and Services Adjunct (MobileHCI'16). ACM, New York, NY, USA, 1021-1025. DOI: http://dx.doi.org/10.1145/2957265.2963118

3. Vassilios S Argyropoulos and Charikleia Kanari. 2015. Re-imagining the museum through "touch": Reflections of individuals with visual disability on their experience of museum-visiting in Greece. ALTER-European Journal of Disability Research/Revue Européenne de Recherche sur le Handicap 9, 2 (2015), 130-143.

4. Serap Buyurgan. 2009. The Expectations of the Visually Impaired University Students from Museums.

Educational Sciences: Theory and Practice 9, 3 (2009), 1191-1204.

5. Giuseppe Ghiani, Barbara Leporini, and Fabio Paternò. 2009. Vibrotactile feedback to aid blind users of mobile guides. Journal of Visual Languages \& Computing 20, 5 (2009), 305-317.

6. Kozue Handa, Hitoshi Dairoku, and Yoshiko Toriyama. 2010. Investigation of priority needs in terms of museum service accessibility for visually impaired visitors. British journal of visual impairment 28, 3 (2010), 221-234.

7. Simon Hayhoe. 2013. Expanding our vision of museum education and perception: An analysis of three case studies of independent blind arts learners. Harvard Educational Review 83, 1 (2013), 67-86.
8. Phoebe Hillemann. 2016. Art Museum Tours For Visitors Who Are Blind - Smithsonian American Art Museum. (2016). https://americanart.si.edu/blog/eye-level/ 2016/09/317/art-museum-tours-visitors-who-are-blind Accessed: 2018-04-11.

9. Dhruv Jain. 2014. Pilot Evaluation of a Path-guided Indoor Navigation System for Visually Impaired in a Public Museum. In Proceedings of the 16th International ACM SIGACCESS Conference on Computers \& Accessibility (ASSETS '14). ACM, New York, NY, USA, 273-274. DOI :

http://dx.doi.org/10.1145/2661334.2661405

10. Catherine Kudlick. 2005. The local history museum, so near and yet so far. (2005).

11. Steven Landau, William Wiener, Koorosh Naghshineh, and Ellen Giusti. 2005. Creating accessible science museums with user-activated environmental audio beacons (Ping!). Assistive Technology 17, 2 (2005), 133-143.

12. The Metropolitan Museum of Art. 2018. For Visitors Who Are Blind or Partially Sighted. (2018).

https://www .metmuseum.org/events/programs/access/ visitors-who-are-blind-or-partially-sighted Accessed: 2018-04-11.

13. Yaniv Poria, Arie Reichel, and Yael Brandt. 2009. People with disabilities visit art museums: an exploratory study of obstacles and difficulties. Journal of Heritage Tourism 4, 2 (2009), 117-129.

14. Kyle Rector, Keith Salmon, Dan Thornton, Neel Joshi, and Meredith Ringel Morris. 2017. Eyes-Free Art: Exploring Proxemic Audio Interfaces For Blind and Low Vision Art Engagement. Proc. ACM Interact. Mob. Wearable Ubiquitous Technol. 1, 3, Article 93 (Sept. 2017), 21 pages. DOI : http://dx.doi.org/10.1145/3130958 